\title{
Physical Activity and Telomere Biology: Exploring the Link with Aging-Related Disease Prevention
}

\author{
Andrew T. Ludlow and Stephen M. Roth \\ Department of Kinesiology, School of Public Health, University of Maryland, College Park, MD 20742-2611, USA \\ Correspondence should be addressed to Stephen M. Roth, sroth1@umd.edu
}

Received 29 September 2010; Revised 18 December 2010; Accepted 30 December 2010

Academic Editor: Ben Hurley

Copyright () 2011 A. T. Ludlow and S. M. Roth. This is an open access article distributed under the Creative Commons Attribution License, which permits unrestricted use, distribution, and reproduction in any medium, provided the original work is properly cited.

\begin{abstract}
Physical activity is associated with reduced risk of several age-related diseases as well as with increased longevity in both rodents and humans. Though these associations are well established, evidence of the molecular and cellular factors associated with reduced disease risk and increased longevity resulting from physical activity is sparse. A long-standing hypothesis of aging is the telomere hypothesis: as a cell divides, telomeres shorten resulting eventually in replicative senescence and an aged phenotype. Several reports have recently associated telomeres and telomere-related proteins to diseases associated with physical inactivity and aging including cardiovascular disease, insulin resistance, and hypertension. Interestingly several reports have also shown that longer telomeres are associated with higher physical activity levels, indicating a potential mechanistic link between physical activity, reduced agerelated disease risk, and longevity. The primary purpose of this review is to discuss the potential importance of physical activity in telomere biology in the context of inactivity- and age-related diseases. A secondary purpose is to explore potential mechanisms and important avenues for future research in the field of telomeres and diseases associated with physical inactivity and aging.
\end{abstract}

\section{Introduction}

Aging is a complex biological phenomenon and the factors governing the process of aging and longevity are only beginning to be understood. Physical inactivity increases the risk of several age-related diseases such as cardiovascular disease (CVD), hypertension, osteoporosis, stroke, and type 2 diabetes [1]. Becoming or remaining physically active in old age has been shown to reduce the risk of morbidity and mortality from these age-related conditions $[2,3]$. Moreover, multiple reports have revealed the lifespan extending potential of physical activity (PA) [4-7]. Consistently performed PA appears to slow the rate of cellular and molecular damage accumulation and blunt the decline in physiological function that is characteristic of the aging process $[8,9]$. Despite these findings, the causal molecular and genetic links between PA and the reduction in age-related disease risk remain elusive.

A potential link between aging and increased disease risk is shortened and/or dysfunctional telomeres. The role of telomeres in several diseases associated with physical inactivity and aging has recently been elucidated [10] and recent epidemiological and experimental evidence points to PA as being able to influence telomere biology [1113]. It should be noted that telomeres are also associated with other diseases, such as neurodegenerative diseases and cancer; however, this review will focus primarily on organ systems involved in diseases associated with physical inactivity and aging such as blood cells and cardiovascular and musculoskeletal systems. In the present review, we will (1) discuss the recent evidence of telomere modulation in physical inactivity- and age-related diseases, (2) describe the relationships observed between telomeres and PA, and (3) explore possible mechanisms underlying these relationships and suggest future research directions.

\section{Telomeres in Aging}

Many hypotheses of aging have been proposed and tested, but no single hypothesis fully explains the complex intricacies of biological aging. A popular model is the "telomere length hypothesis" of aging that is set within the context of 
cellular senescence. Telomeres are repeated DNA sequences $\left(5^{\prime}-\mathrm{TTAGGG}_{\mathrm{n}}-3^{\prime}\right)$ found on the ends of linear chromosomes that protect the ends of DNA from damage during replication. Telomeres also act as a "mitotic clock" [14], shortening with every cell division until cellular senescence occurs (i.e., critically short telomeres lead to senescence, where a cell is metabolically active but unable to repair damage or divide). As the senescent population of cells in a tissue increases with advancing age, the function of the tissue becomes impaired and displays an aged phenotype [15]. Thus, telomeres and their length are considered at minimum an important aging biomarker but may also act as a critical mechanism for age-related decline $[10,16-18]$; however, whether short telomeres are cause or consequence of typical physiological aging and age-related disease is yet to be determined. Beyond aging, shortened telomeres are implicated in genetic syndromes such as dyskeratosis congenita [19,20], Werner syndromes [21, 22], and aplastic anemia [23]. Also several studies have identified gene variants in the telomere-related proteins that are associated with altered telomere lengths [24-27]; their role in the predisposition to age- and diseaserelated traits is unclear at this time.

Telomere length is highly variable among mammalian species and among tissues within a species [28]. Human telomeres are typically 5-12 kilobases in length [29], while mouse and rat telomeres are much longer (up to 150 kilobases depending on inbreeding status and strain) [28]. This is important to consider when interpreting telomere data from animal studies, as telomere length dynamics between mice and humans are different, though mouse models with shorter telomeres are an important resource in the study of comparative telomere biology $[28,30]$. In humans, tissue-specific telomere length is detectable at birth with a rate of attrition estimated at 30-150 base pairs per year in leukocytes and fibroblasts [31,32]. Telomeres shorten during DNA replication due to the end-replication problem, in which the DNA polymerase enzyme cannot fully copy the end of the DNA strand during DNA replication associated with mitosis and cell division [31].

In certain cells with high mitotic activity (e.g., germ line and progenitor cells; immune cells), the end-replication problem is overcome by the enzyme telomerase that maintains telomere length homeostasis by adding $5^{\prime}$-TTAGGG-3' repeats to telomeres following DNA replication [33]. Telomerase is a ribonucleoprotein complex consisting of an enzymatically active protein component (TERT) and an RNA template (TERC) [34]. Telomerase knockout mice (both Tert and Terc knockouts) have been developed and used as models for several age-related diseases, with $\mathrm{Tert}^{-1-}$ animals identified as a model of CVD [35]. A recent study has shown that TERT reactivation in aged TERT-deficient mice was able to alleviate signs of aging showing the importance of the telomere system in tissue health and aging [36] and providing further evidence for telomere shortening as a likely factor in age-associated organ decline and disease risk [36-38]. Though telomerase typically has low activity in postmitotic cells, telomerase is activated along with the expression of other oncogenes (e.g., MYC, RAS) in most cancers and immortalized cell lines. This results in a paradoxical role for telomerase, with critical functions in both health and disease depending on the cell type $[39,40]$.

Telomeres are protected by a six-protein complex termed "shelterin", which functions to monitor telomere length and protect DNA telomere ends from being recognized by DNA damage response proteins and nucleases [41]. Shelterin is also involved in cell cycle regulation and is important for maintenance of cell viability [41]. Shelterin consists of six key proteins bound to chromosome ends, including three components that interact directly with telomere DNA: telomere-repeat binding factors 1 and 2 (TRF1 and TRF2) and protection of telomeres 1 (POT1). In addition, shelterin includes three additional proteins that each interact with the three telomere DNA-binding proteins. The regulation of telomere length by telomerase and shelterin components is critical in determining cellular fate.

Recent studies have associated various aspects of telomere biology (e.g., telomere length and expression of telomererelated gene products) to diseases of aging, including but not limited to CVD and CVD risk factors, diabetes phenotypes, and musculoskeletal diseases. Many of these same diseases and risk factors have also been associated with an inactive lifestyle. Physical activity and exercise training have been associated not only with prevention and improvement of disease symptoms but also with telomere length, indicating a possible role for PA influencing telomere biology as a potential mechanism for prevention or delay of age-related disease. Figure 1 presents an overview of the major factors in the regulation of telomere biology as related to both agerelated diseases and cancer. The research described below shows a clear association of shortened telomere length with diseases associated with aging and inactivity, though future research is needed to determine if telomere shortening is an etiology of these diseases.

\section{Telomeres and Age- and Inactivity-Related Diseases}

3.1. Telomeres and Cardiovascular and Metabolic Disease Risk Factors. Cardiovascular disease and its risk factors represent a major proportion of the population's disease burden during aging and $\mathrm{PA}$ is a potent means of reducing the risk of developing CVD. Thus, CVD and other CVD risk factors are considered diseases of both physical inactivity and aging. Several studies have associated shortened telomere length in peripheral blood mononuclear cells (PBMCs) and other tissues to hypertension and other CVD risk factors. A common hypothesis is that leukocyte telomere length reflects the overall systemic burden of oxidative stress and inflammation, which are two key risk factors for CVD, thus providing a potential physiological link between telomeres and CVD [42].

For example, Jeanclos et al. [43] showed a relationship in twins that telomere length was inversely related to pulse pressure. Aviv et al. [44] showed that abdominal aorta cells displayed telomere shortening as a function of age indicating an age-dependent loss of vascular cell function. Benetos et al. showed over multiple studies in 


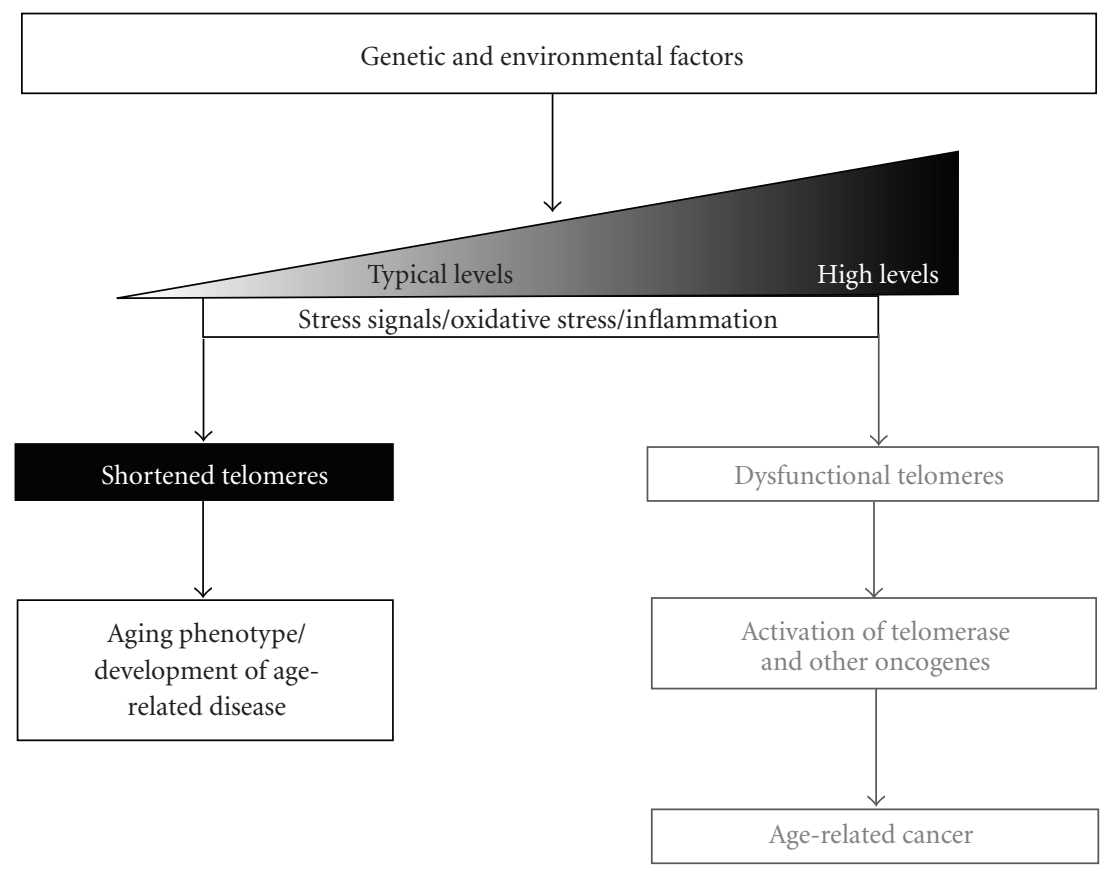

FIGURE 1: The major factors leading to age-related disease or cancer phenotypes are shown. Interaction of genetic and environmental factors can lead to varying levels of DNA damage, oxidative stress, and inflammation, all of which can contribute to shortened or dysfunctional telomeres, depending on the extent of damage. Typically-shortened telomeres can result in cell cycle arrest, tumor suppression, and loss of functional tissue via senescence or apoptosis/necrosis and an aging phenotype. At the extreme, DNA damage (e.g., gene mutations) and subsequent activation of oncogenes, such as TERT and telomerase activity, can lead to age-related cancer. Becoming or remaining physically active may prevent or delay the onset of many age-related diseases and even some cancers, potentially through protection of telomeres.

men that higher pulse wave velocity and pulse pressure [16], carotid artery plaques [45], and plasma aldosterone levels [46] were associated with shorter telomeres. Patients with chronic heart failure have also been observed to have shorter leukocyte telomere lengths [47]. In the Framingham Heart Study and the Cardiovascular Health Study shorter telomere lengths were associated with increased oxidative stress, insulin resistance, and hypertension [48, 49]. In two other studies by the Aviv group in the Framingham Heart Study shorter telomeres were associated with increased renin-aldosterone ratios and to carotid artery thickness in men $[50,51]$. In an interesting study of the inheritance of telomere length, Brouilette et al. [52] measured telomere length in the healthy offspring of both coronary artery disease (CAD) patients and nondiseased controls. The results revealed shorter leukocyte telomere lengths in the offspring of CAD patients compared to the offspring of healthy controls. The authors showed that offspring telomere length was significantly associated with parental telomere length and that the telomere length difference between the two groups represented the equivalent of 17 years of telomere length attrition [52]. Brouilette et al. [53] also showed that statin use significantly reduced telomere shortening in CVD patients and that telomere length may be a good predictor of successful statin treatment. In a cross-sectional study of young and older men, the angiogenic $\mathrm{CD} 31+$ cell fraction of PBMCs were isolated and characterized for telomere length, telomerase enzyme activity, and various cellular function phenotypes. The results showed that older men had shorter $\mathrm{CD} 31+$ telomere lengths and were more susceptible to apoptotic stimuli compared to the younger men [54]. This study provides an important link between telomeres, angiogenic cells, aging, and risk for CVD by showing decreased stress resistance and cellular function concordant with reduced telomere length. Interestingly, Ornish et al. [55] showed that a lifestyle intervention including exercise and low-fat diet was able to lower LDL cholesterol levels and increase telomerase activity in leukocytes. Though preliminary, these data indicate that lifestyle intervention, through a reduction in systemic oxidative stress and inflammation, may increase telomerase activity and telomere maintenance.

Two recent longitudinal studies in separate cohorts of CVD-affected individuals have confirmed the crosssectional findings described above, but with an unanticipated complexity $[10,56]$. Farzaneh-Far et al. demonstrated that the most potent predictors of telomere shortening in CVD patients were age, male sex, and increased waist-to-hip ratio [10]. Surprisingly, only a portion of the patients showed the expected telomere shortening, and telomere length was shown to be maintained or even lengthened with advancing age in some individuals, showing that in vivo telomere dynamics are more complex than a simple, predictable shortening of the mitotic clock $[10,56]$. Vasan et al. [42] and Kuznetsova et al. [57] also recently observed longer leukocyte telomere length in individuals with left ventricular hypertrophy. The groups speculate that longer 
telomere lengths in diseased patients may be due to an increased reserve potential of angiogenic progenitor cells in individuals with left ventricle hypertrophy, since left ventricle hypertrophy is highly dependent on angiogenesis, or altered levels of growth factors (e.g., IGF-1) and activation of telomerase. The unexpected findings in longitudinal studies that telomeres can take three different trajectories (expected shortening, maintenance, and lengthening) deserve special attention. Designing studies to elucidate the underlying factors associated with the different telomere trajectories and the cellular outcomes will provide insight into our understanding of whether telomere dynamics are cause or consequence in the progression of CVD.

Multiple studies have also associated telomere length with the presence of type II diabetes and diabetes-related phenotypes (e.g., insulin resistance and impaired glucose tolerance). Risk factors for and symptoms of type II diabetes, including impaired glucose tolerance, increased levels of glycosylated hemoglobin, and increased adiposity, have been associated with shorter telomeres in leukocytes [58-61]. AlAttas et al. showed that higher HOMA-IR values in males and reduced serum levels of adiponectin in females were the best predictors of shortened telomere length in leukocytes [62]. In subjects with CAD but with or without metabolic syndrome, it was observed that telomere length and telomerase enzyme activity were lower and oxidative DNA damage (8-oxo-deoxyguanine) higher in endothelial progenitor cells from those CAD patients with metabolic syndrome [63]. In a cohort of women, Epel et al. [64] associated stress arousal and CVD risk factors to lower telomerase enzyme activity and shorter telomeres. Specifically lower telomerase enzyme activity was associated with higher fasting glucose, poor lipid profile, increased abdominal adiposity, and a composite metabolic syndrome variable. Shorter telomeres were also associated with increased levels of circulating stress hormones (cortisol and catecholamines).

In two studies by Tarry-Adkins et al. [65, 66], the researchers showed in two different tissue types that poor maternal nutrition can influence telomere length of the offspring. Since poor maternal nutrition and the subsequent "catch-up growth phase" are associated with increased risk of CVD and type II diabetes, the authors tested the hypothesis that telomeres would be shorter in offspring of nutritionally deprived mothers. They observed that telomere length was shorter in aorta and pancreatic islets in the offspring of animals with poor maternal nutritional status that were undergoing catch-up growth compared to control offspring. More recently Salpea et al. [67] showed that individuals with type II diabetes had shorter telomere lengths than controls and telomere length was positively correlated with total antioxidant levels in patient leukocytes. Oxidative stress, which is known to shorten telomeres and to be higher in type II diabetics, may provide a link between disease and telomere length. These data indicate that altered metabolic status induced by type II diabetes and related traits is associated with shorter telomeres, though, similar to CVD, whether or not losses of telomere length are a cause or consequence of metabolic disease is unclear.
3.2. Telomeres and Musculoskeletal Diseases Associated with Physical Inactivity and Aging. The losses of bone mineral density and skeletal muscle mass with advancing age have important consequences for morbidity and mortality in older men and women. Fewer studies of telomere biology have been performed in these tissues, but the results generally indicate a similar association to that observed for CVD and metabolic disease. For example, several studies have associated reduced bone mineral density and shortened telomere length in both men and women [68, 69]. In a longitudinal study of 84 men, researchers observed a positive correlation between age-adjusted leukocyte telomere length and distal forearm bone mineral density [68]. Other studies have not observed an association between telomere length and markers of bone health, including a Health ABC study in which telomere length was not associated with markers of bone health over a five-year period [70, 71]. The cell type examined in those studies (leukocytes) may, however, confound the results in that bone tissue telomere length or bone progenitor cell telomere length may be a better indicator of bone health. For instance, chondrocytes of aged or diseased (osteoarthritic) individuals near the osteoarthritic lesions had shorter telomere lengths and exhibited increased evidence of cell senescence than cells farther from the lesions [72].

Few studies have examined telomere length in sarcopenia or other skeletal muscle phenotypes. Skeletal muscle is unique in that it consists of multinucleated muscle fibers and multiple niche populations of singularly nucleated cell types, the most well-characterized being satellite cells [73]. Skeletal muscle is also considered to be postmitotic, with only the satellite cells actively dividing when new nuclei are needed within the skeletal muscle fiber. When skeletal muscle satellite cells are activated to divide and incorporate into muscle fibers as new myonuclei, the fibers' average telomere length is reduced $[73,74]$. The newly added satellite cell nuclei represent the nuclei with the shortest telomeres since these newly added nuclei would have been actively dividing over time [73, 74]. Minimum telomere length in skeletal muscle is thus thought to represent the replicative history of satellite cells [75]. As such, over time skeletal muscle telomere length can change despite its postmitotic condition $[73,76,77]$.

Thus, when measuring skeletal muscle telomere length, mean and minimum telomere length (i.e., the shortest of the lengths observed in a tissue sample), representing fiber telomere length and satellite cell telomere length, respectively, must be analyzed and interpreted correctly [73]. A recent investigation showed that skeletal muscle telomere length was reduced in elderly individuals compared to young controls, as well as a modest trend for shorter skeletal muscle homogenate telomere lengths in sarcopenic compared to nonsarcopenic individuals [78]. Other studies in skeletal muscle have focused on the replicative potential and regenerative capacity of satellite cells rather than skeletal muscle per se. For example, Wernig et al. studied the regenerative capacity of satellite cells and showed a slight decrease in mean telomere length with age in those cells, corresponding to reduced regenerative capacity [79]. Data 
from several different muscular dystrophies indicate shortened satellite cell and skeletal muscle homogenate telomeres and telomere-related dysfunction associated with the muscle degradation and atrophy $[77,80,81]$. When considered together, these studies indicate that skeletal muscle telomere length can change and moreover that using diseases such as muscular dystrophies as extreme skeletal muscle remodeling models may provide an avenue to understand the complex skeletal muscle telomere biology landscape [82]. The role of telomeres and telomerase in skeletal muscle and satellite cells was reviewed recently [73].

\section{Telomeres and Physical Activity}

As shown in Table 1, several reports, including one from our laboratory, have associated PA or exercise training with alterations in telomere length and/or the network of proteins that interact with telomeres [11, 12, 73, 76, 83-85]. These results provide evidence of a link between PA and aging at the cellular level and indicate the possibility of a mechanistic link between the influences of PA in the attenuation of agerelated diseases.

Collins et al. [76] were the first to demonstrate an association of telomere length with physical activity when they reported excessive telomere shortening in skeletal muscle of endurance athletes with severe fatigued athlete myopathic syndrome (FAMS) compared to age- and training volume-matched athletes. In a follow-up study by the Collins group, shorter minimum telomere lengths were observed in those endurance athletes with the highest number of years and hours spent training [85]. These results indicate that long-term endurance training by highly trained athletes may be a significant stressor to skeletal muscle and/or satellite cell telomeres, as indicated by the shorter minimum telomere lengths.

Beginning in 2008, a number of groups began to study the association of typical, moderate physical activity with telomere length in humans. Ponsot et al. [86] investigated skeletal muscle telomere length in physically active and inactive men and women in two age groups, young and old, and observed that telomere length was similar within an age group regardless of activity level, indicating that moderate PA is not detrimental to skeletal muscle telomere length. In epidemiological studies by Cherkas et al. [11] and Ludlow et al. [12] a positive association between PA and leukocyte telomere length was observed up to moderate levels of typical $\mathrm{PA}$, while high levels of PA were associated with shorter PBMC telomere lengths [12]. These results were not fully replicated in a large cohort of older Chinese individuals $(\sim 72 \mathrm{yr}$ old $)$, though telomere length tended to be lowest in the group with the lowest PA level $(P=0.09)$ [88]. Whether that study was impacted by a "ceiling" effect by examining only older individuals is possible. Nevertheless, these studies provided the first evidence of a potential benefit of moderate PA on telomere biology.

Additional evidence for a role of PA in telomere biology has emerged in more recent studies. For example, a recent study reported that physically active women had longer leukocyte telomere lengths compared to sedentary individuals, which the authors hypothesized was related to PA diminishing the potential influence of perceived psychological stress [94] on leukocyte telomere length [90]. In addition, a study investigating telomere length and PA in adolescent males and females observed that African American females who spent more time performing vigorous PA had significantly longer telomeres than less active peers [91]. LaRocca et al. [84] showed that leukocyte telomere length was longer in older endurance exercise-trained individuals compared to sedentary age-matched controls and was not different from young-trained individuals and that telomere length was related to maximal aerobic exercise capacity [84]. Finally, Song et al. [92] reported that lifestyle factors (e.g., exercise level, smoking, body mass index) correlated with newly defined biomarkers [95] of DNA damage and telomere dysfunction in blood cells.

Other investigations have attempted to associate telomere alterations to resistance exercise. Kadi et al. [87] studied competitive powerlifters compared to recreationally active individuals and both average and minimum telomere lengths of vastus lateralis muscle in the powerlifters were shown to be longer compared to the controls. In contrast, within the group of powerlifters minimum telomere length was inversely associated to personal records in the squat and deadlift, indicating that the greater the weight lifted in a maximum effort, the shorter the minimum telomere length. It should be noted that resistance training and unfamiliar lengthening contractions are known to cause cellular damage to skeletal muscle [96] and activate satellite cell proliferation for regenerative purposes $[97,98]$. One would assume that this would result in telomere shortening of the satellite cell telomeres due to cell proliferation, with the new nuclei incorporated into the muscle fiber representing the shortest telomeres in the regenerated muscle fiber; however this was apparent only in the strongest powerlifters [87]. Though speculative, the long-term training in the powerlifters seems to have resulted in a protective effect on telomere length in skeletal muscle, while excessive training associated with elite-level performance may result in accelerated telomere shortening.

Animal models have also provided evidence of a role of physical activity in modifying telomere biology. Although rodents tend to have significantly longer telomeres compared to humans [28], the associated proteins and overall telomere biology between the species are similar, thus providing useful insights into possible regulatory mechanisms. Werner et al. [13] recently showed that the cardioprotective effects of voluntary wheel running on cardiomyocytes were conferred by an exercise-induced increase in telomere binding proteins (shelterin) and telomerase enzyme activity mediated by the presence of telomerase protein component TERT as well as IGF-1 and eNOS. Exercise was also shown to decrease markers of apoptosis and reduce gene expression of several cell cycle associated genes, showing that exercise induces an antiapoptotic environment thus preserving functional tissue and delaying an aged phenotype [13]. Cardiomyocyte telomere length itself was not different between exercise and sedentary groups but was different with age ( 3 months versus 18 months), indicating age-related telomere shortening. In 
TABLE 1: Summary of studies investigating physical exercise and telomere-related traits.

\begin{tabular}{|c|c|}
\hline Study & Major findings \\
\hline \multicolumn{2}{|c|}{ Human skeletal muscle } \\
\hline Collins et al. [76] & $\begin{array}{l}\text { Shorter telomeres in VL of subjects with Fatigued Athlete Myopathic Syndrome } \\
\text { (FAMS) }\end{array}$ \\
\hline Ponsot et al. [86] & Equal VL telomere length between sedentary and active individuals \\
\hline Kadi et al. [87] & $\begin{array}{l}\text { Longer VL telomeres (mean and minimum) in powerlifters compared to sedentary } \\
\text { men }\end{array}$ \\
\hline \multicolumn{2}{|c|}{ Human leukocytes (WBC unless otherwise noted) } \\
\hline Cherkas et al. [11] & Longer telomeres in more active individuals \\
\hline Ludlow et al. [12] & $\begin{array}{l}\text { Longer PBMC telomeres in moderately active individuals compared to both } \\
\text { sedentary and high active }\end{array}$ \\
\hline Woo et al. [88] & No difference in telomere length between active and sedentary individuals \\
\hline Shin et al. [89] & $\begin{array}{l}\text { No difference in telomere length in obese middle age women who underwent } 6 \\
\text { months of aerobic exercise training compared to sedentary controls }\end{array}$ \\
\hline Werner et al. [83] & Longer PBMC telomeres in older athletes compared to older sedentary individuals \\
\hline Puterman et al. [90] & Longer telomeres in active individuals with lowest psychological stress levels \\
\hline Zhu et al. [91] & $\begin{array}{l}\text { Longer telomeres in active adolescent African American females compared to less } \\
\text { active peers }\end{array}$ \\
\hline LaRocca et al. [84] & Longer telomeres in older active individuals compared to sedentary peers \\
\hline Song et al. [92] & $\begin{array}{l}\text { Longer telomeres positively correlated with lifestyle factors such as PA level, BMI } \\
\text { and smoking status }\end{array}$ \\
\hline
\end{tabular}

Rodent Tissues

Radak et al. [93]

Werner et al. [13]

Werner et al. [83]
No change in telomerase activity with chronic (8 weeks) swimming in rat skeletal muscle or liver

Increased telomere protection and reduced apoptotic signaling in myocardium after VWR; elucidation of possible mechanisms

Increased telomere protection and reduced apoptotic signaling in aorta tissue after VWR; confirmation of possible mechanisms observed in Werner et al. [13]

VL: vastus lateralis; WBC: white blood cells; PBMC: peripheral blood mononuclear cells; PA: physical activity; BMI: body mass index; VWR: voluntary wheel running.

a follow-up study in aortic tissues of mice and mononuclear cells of humans, Werner et al. [83] again showed that exercise training increased telomerase enzyme activity, increased telomere binding protein and mRNA expression, and decreased levels of Chk2, p16, and p53 in mouse aorta. These gene expression changes were again shown to be mediated by TERT and eNOS in the aorta. Similar to the cardiomyocyte data, aortic telomere length was not altered by 3 weeks or 6 months of voluntary wheel running but demonstrated age-related shortening (3 months versus 18 months). In the human arm of the study, the authors investigated young sedentary, young athletes, aged sedentary, and aged athlete groups for telomere-related outcomes. Mononuclear cell telomere length was preserved in the aged athletes and was shortest in the aged sedentary individuals, and telomerase activity was greater in young and aged athletes compared to the age-matched sedentary individuals. Telomere-repeat binding protein 2 (TRF2) expression was increased in the athletes compared to sedentary individuals, while cell cycle genes (e.g., p16, p53, Chk2) were reduced in the athletes compared to the inactive groups [83].

In summary, these human and animal experimental and epidemiological results, most notably the papers by Werner and coworkers, indicate that exercise training is a potent stimulus to the telomere biology system, though influences on telomere length itself may not be seen unless the training is for a long duration. The data also indicate the possibility that moderate PA may provide the greatest positive influence on telomere biology while higher levels of exercise training may have a negative effect.

\section{Possible Mechanisms of Physical Activity-Induced Modifications of Telomere Biology}

Few studies have defined direct cellular and molecular mechanisms of the effect of PA on the biology of aging, though as outlined above a slowing of telomere degradation may act as one potential mechanism. The direct signaling pathways by which PA interacts with the telomere are not clearly delineated, though the work of Werner et al. has provided some initial insights. In general, regular PA is thought to prevent and delay inactivity- and age-related disease through multiple mechanisms, with reductions in either oxidative stress [6] or inflammation [99] or both being key potential mediators. These same pathways can be linked to changes in telomere biology, providing potential mechanisms by which 
PA influences telomere biology with downstream influences on disease development and progression.

For example, exercise training increases antioxidant capacity via an increase in antioxidant enzyme activity [100102]. Telomere shortening is exacerbated in numerous cell types due to oxidative stress [103-106]. Besides proliferation, telomeres can also shorten due to unrepaired damage from such oxidative stress, which could explain telomere shortening in postmitotic tissues such as neurons, myocardium, and skeletal muscle $[13,103,107,108]$. Thus, telomere length may be maintained in moderately physically active individuals due to reductions in oxidative damage occurring to the telomere. Telomerase is also responsive to oxidative stress and may be key to protecting cells from stress insults $[109,110]$; so this component of the telomere system may also benefit from the reduction in oxidative stress associated with PA.

In the studies by Werner et al. [13, 83], a role for endothelial nitric oxide synthase has been described, such that the presence of eNOS, and assumed nitric oxide (NO) bioavailability, is critical for the exercise-induced alterations to the telomere binding proteins in cardiomyocytes and aortic tissue in mice. These findings indicate that exercise, mediated by the beneficial effects of NO, is able to confer oxidative stress resistance and reduced apoptosis in multiple tissue types via genome stabilization by an increased expression of telomere binding proteins and telomerase by activation of cell survival pathways. Nitric oxide signaling via cGMP is able to activate several prosurvival protein kinases including phosphatidylinositol $3^{\prime}$ kinase (PI-3K) and protein kinase B (AKT) [111]. These studies by Werner et al. also showed a role for IGF-1 in the activation of telomerase. Recent epidemiological evidence indicates that older individuals with low circulating IGF-1 and free of overt disease have shorter leukocyte telomere lengths [112]. Since acute exercise stimulates expression of IGF-1 from both skeletal muscle and liver [113], IGF-1 may be playing a role in the augmentation of telomere biology by exercise. How the "exercise signal" is transmitted via prosurvival pathways to the telomere-related genes has not been defined; however, these recent findings have highlighted possible molecular underpinnings of the beneficial effects of exercise training on vascular phenotypes.

Exercise of all types can activate AMP-activated protein kinase (AMPK) $[114,115]$ and mammalian target of rapamycin (mTOR) $[116,117]$. Both of these pathways regulate gene expression of several genes, are energy sensitive, and are involved in cellular aging $[118,119]$. Interestingly, these pathways are involved in insulin signaling, protein synthesis (mRNA translation), and cell growth and survival, which makes these pathways important targets to consider when studying telomeres. For instance, telomerase has been shown to be associated with altered levels of AMPK [120]. These pathways deserve special attention with regard to the linkages between exercise, telomere biology, and cellular aging.

Stress hormones such as cortisol and stress responsive pathways such as those of the mitogen-activated kinases (MAPK) have also been implicated in telomere biology [121,
122]. For instance, Spallarossa et al. [122] demonstrated that p38 MAPK was involved in the regulation of $\operatorname{Tr} f 2$ gene expression in response to doxorubicin treatment in cardiomyocytes. Acute exercise is known to activate MAPK signaling, though the effects of exercise training on MAPK are less clear [123]. So acute exercise may result in a repression of telomere binding protein expression, which is consistent with longer telomeres [124]. The MAPK pathway should be investigated as a possible mechanism by which exercise can influence telomere biology.

In addition to oxidative stress-related pathways, short telomeres may contribute to the chronic inflammatory phenotype associated with aging, as demonstrated recently in a study showing shortened telomeres implicated in the regulation of interferon-stimulated gene 15 (ISG-15) [125]. Lou et al. used a customized microarray analysis of cells with short, normal, and artificially elongated telomeres to elucidate genes differentially expressed in human skin fibroblasts and ISG-15 was clearly differentially expressed in relation to telomere length. Several studies have linked the expression and secretion of ISG-15 to inflammation through its stimulation of the proinflammatory interferon, IFN $\gamma[126,127]$. These results point to a possible mechanism whereby shortened telomeres are causing an increase in inflammation (a condition associated with many age-related diseases), thus contributing directly to the disease process. A recent study using $m \mathrm{Tert}^{-1-}$ cells with shortened telomeres showed enhanced toll-like receptor 4 (TLR4) expression [128]. TLR4 mediates the inflammation process by stimulating the expression of NF- $\kappa \mathrm{B}$, which initiates the transcription of several proinflammatory genes such as Il-6, COX2, and TNF- $\alpha$. Thus, shortened telomeres have been linked to a proinflammatory cellular environment.

In contrast, acute and chronic moderate exercise training is associated with beneficial changes in inflammatory makers $[129,130]$, pointing to a possible protective effect of PA against telomere shortening through reduced inflammationrelated gene expression. Several inflammatory cytokines have been shown to be augmented in age-related diseases (e.g., TNF-alpha), and PA may blunt these age-related changes in inflammatory cytokines [131]. Short telomeres may initiate a feed-forward mechanism resulting in the expression of both inflammatory and oxidative stress pathways that could accelerate telomere shortening and enhance age- and inactivity-related disease phenotypes. Thus, PA may be exerting its antiaging effects by protecting telomeres from shortening by improvements in antioxidant capacity and chronic inflammation.

Determining whether or not telomere shortening is causing cellular dysfunction and age-related disease or if telomere length is simply a bystander reflecting the hostile cellular environment associated with age-related disease is a challenge. The phenotypes of early generation $\mathrm{Tert}^{-/-}$and $\mathrm{Terc}^{-1-}$ knockout mice do not display telomere shortening as expected, but later generations of these animals have shortened telomeres and overt phenotypes such as CVD, indicating a direct link between telomere shortening and disease $[132,133]$. These and other knockout animal models may provide insights into whether or not shortened telomeres 
are responsible for diseases of aging and inactivity. Other possibilities include engineering tissue-specific knockout animals for components of the shelterin complex. Wholebody knockouts for $\operatorname{Tr} f 1$ and $\operatorname{Tr} f 2$ have been attempted but have not survived past the embryonic stage [134, 135], showing vital roles for these proteins in development. In contrast, tissue-specific shelterin component knockout mouse strains produce viable offspring that display aging phenotypes and cancer $[124,136]$. Tissue-specific knockout animals could be exposed to PA intervention studies to further elucidate the role of PA in telomere biology.

\section{Conclusions and Future Directions}

The majority of existent literature concerning telomere length in human epidemiology to date has focused on a sample of convenience, namely, white blood cells or more specifically PBMCs. Peripheral blood mononuclear cells are easily obtained via venipuncture and simple isolation procedures. The main reasons these cells have become a staple in human telomere research are their ease of acquisition and, as immune cells, they are a cell type active during the disease process and thus demonstrate telomere shortening. These cells have related limitations, however, in that immunological cells may be a better marker of systemic inflammation rather than of age-related disease itself [137] and may not be representative of the telomere length trajectory of other tissues. Thus future studies would be improved by studying tissueand cell-specific telomere biology in relation to disease by obtaining biopsy specimens, or working in established animal or cell culture models of disease, to elucidate specific pathways, signals, and environmental stimuli contributing to age- and inactivity-related disease traits.

The evidence for a modification of telomeres in several inactivity- and aging-related diseases is clear. The possible mechanisms for these alterations in telomere biology are multifactorial and include oxidative stress, growth- and stress-related hormones and their associated pathways, and inflammation, though the direct mechanistic pathways have yet to be identified with each disease. The connection between the exercise-induced changes in telomere biology and age- and inactivity-related diseases has yet to be elucidated, but considerable indirect evidence indicates the potential for PA to improve cellular conditions and thus reduce disease risk through impacts on telomere biology.

Future studies should focus on telomere dynamics in response to acute, moderate, and long duration (life-long) exercise trials in animal models and where possible in humans to clarify potential mechanisms, with emphasis on longitudinal study designs with repeated measures of telomere length and other age- or disease-related outcomes. Exercise of different intensities should also be explored at various time points across the life span, as some literature indicates differential influences on telomere biology depending on intensity. Human trials will necessarily involve long durations to allow measurement of telomere length changes, though examination of telomere-related components can be studied with shorter durations. The factors responsible for the exercise-induced alterations in telomere binding proteins are yet to be fully elucidated, which offers an open avenue of research. Exercise is known to prevent or delay many agerelated diseases such as CVD and type II diabetes, which in turn have been linked to telomeres. The question of whether or not telomeres and associated proteins are causing the disease progression or are simply altered as a result of diseaserelated processes is open for debate. What is clear is that exercise slows or prevents symptoms of age-related diseases and is also able to alter telomere biology. Deciphering the role of exercise in altering telomere biology in inactivity- and age-related disease progression holds promise for continued understanding of exercise training as a critical tool for the prevention and treatment of these diseases.

\section{Acknowledgment}

A. T. Ludlow was supported by a National Institutes of Health predoctoral training fellowship (AG000268).

\section{References}

[1] P. T. Katzmarzyk and I. Janssen, "The economic costs associated with physical inactivity and obesity in Canada: an update," Canadian Journal of Applied Physiology, vol. 29, no. 1, pp. 90-115, 2004.

[2] S. N. Blair, H. W. Kohl, R. S. Paffenbarger, D. G. Clark, K. H. Cooper, and L. W. Gibbons, "Physical fitness and all-cause mortality: a prospective study of healthy men and women," Journal of the American Medical Association, vol. 262, no. 17, pp. 2395-2401, 1989.

[3] F. W. Booth, S. E. Gordon, C. J. Carlson, and M. T. Hamilton, "Waging war on modern chronic diseases: primary prevention through exercise biology," Journal of Applied Physiology, vol. 88, no. 2, pp. 774-787, 2000.

[4] J. O. Holloszy, "Exercise and longevity: studies on rats," Journals of Gerontology, vol. 43, no. 6, pp. B149-B151, 1988.

[5] I. M. Lee, R. S. Paffenbarger, and C. H. Hennekens, "Physical activity, physical fitness and longevity," Aging, vol. 9, no. 1-2, pp. 2-11, 1997.

[6] A. Navarro, C. Gomez, J. M. López-Cepero, and A. Boveris, "Beneficial effects of moderate exercise on mice aging: survival, behavior, oxidative stress, and mitochondrial electron transfer," American Journal of Physiology, vol. 286, no. 3, pp. R505-R511, 2004.

[7] D. E. R. Warburton, C. W. Nicol, and S. S. D. Bredin, "Health benefits of physical activity: the evidence," Canadian Medical Association Journal, vol. 174, no. 6, pp. 801-809, 2006.

[8] T. B. L. Kirkwood, "Molecular gerontology," Journal of Inherited Metabolic Disease, vol. 25, no. 3, pp. 189-196, 2002.

[9] Z. Radák, H. Naito, T. Kaneko et al., "Exercise training decreases DNA damage and increases DNA repair and resistance against oxidative stress of proteins in aged rat skeletal muscle," Pflugers Archiv European Journal of Physiology, vol. 445, no. 2, pp. 273-278, 2002.

[10] R. Farzaneh-Far, J. Lin, E. Epel, K. Lapham, E. Blackburn, and M. A. Whooley, "Telomere length trajectory and its determinants in persons with coronary artery disease: iongitudinal findings from the heart and soul study," PloS one, vol. 5, no. 1, Article ID e8612, 2010.

[11] L. F. Cherkas, J. L. Hunkin, B. S. Kato et al., "The association between physical activity in leisure time and leukocyte 
telomere length," Archives of Internal Medicine, vol. 168, no. 2, pp. 154-158, 2008.

[12] A. T. Ludlow, JO. B. Zimmerman, S. Witkowski, J. W. Hearn, B. D. Hatfield, and S. M. Roth, "Relationship between physical activity level, telomere length, and telomerase activity," Medicine and Science in Sports and Exercise, vol. 40, no. 10, pp. 1764-1771, 2008.

[13] C. Werner, M. Hanhoun, T. Widmann et al., "Effects of physical exercise on myocardial telomere-regulating proteins, survival pathways, and apoptosis," Journal of the American College of Cardiology, vol. 52, no. 6, pp. 470-482, 2008.

[14] L. Hayflick, "The limited in vitro lifetime of human diploid cell strains," Experimental Cell Research, vol. 37, no. 3, pp. 614-636, 1965.

[15] J. Pedro De Magalhães, "From cells to ageing: a review of models and mechanisms of cellular senescence and their impact on human ageing," Experimental Cell Research, vol. 300, no. 1, pp. 1-10, 2004.

[16] A. Benetos, K. Okuda, M. Lajemi et al., "Telomere length as an indicator of biological aging the gender effect and relation with pulse pressure and pulse wave velocity," Hypertension, vol. 37, no. 2, pp. 381-385, 2001.

[17] E. H. Blackburn, "Telomeres and telomerase," Keio Journal of Medicine, vol. 49, no. 2, pp. 59-65, 2000.

[18] R. C. Allsopp, H. Vaziri, C. Patterson et al., "Telomere length predicts replicative capacity of human fibroblasts," Proceedings of the National Academy of Sciences of the United States of America, vol. 89, no. 21, pp. 10114-10118, 1992.

[19] M. Armanios, J. K. Alder, E. M. Parry, B. Karim, M. A. Strong, and C. W. Greider, "Short telomeres are sufficient to cause the degenerative defects associated with aging," American Journal of Human Genetics, vol. 85, no. 6, pp. 823-832, 2009.

[20] S. A. Savage, N. Giri, G. M. Baerlocher, N. Orr, P. M. Lansdorp, and B. P. Alter, "TINF2, a component of the shelterin telomere protection complex, is mutated in dyskeratosis congenita," American Journal of Human Genetics, vol. 82, no. 2, pp. 501-509, 2008.

[21] S. Chang, "A mouse model of Werner Syndrome: what can it tell us about aging and cancer?" International Journal of Biochemistry and Cell Biology, vol. 37, no. 5, pp. 991-999, 2005.

[22] S. Chang, A. S. Multani, N. G. Cabrera et al., "Essential role of limiting telomeres in the pathogenesis of Werner syndrome," Nature Genetics, vol. 36, no. 8, pp. 877-882, 2004.

[23] R. T. Calado and N. S. Young, "Mechanisms of disease: telomere diseases," New England Journal of Medicine, vol. 361, no. 24, pp. 2308-2365, 2009.

[24] V. Codd, M. Mangino, P. Van Der Harst et al., "Common variants near TERC are associated with mean telomere length," Nature Genetics, vol. 42, no. 3, pp. 197-199, 2010.

[25] Y. Matsubara, M. Murata, K. Watanabe et al., "Coronary artery disease and a functional polymorphism of hTERT," Biochemical and Biophysical Research Communications, vol. 348, no. 2, pp. 669-672, 2006.

[26] Y. Matsubara, M. Murata, T. Yoshida et al., “Telomere length of normal leukocytes is affected by a functional polymorphism of hTERT," Biochemical and Biophysical Research Communications, vol. 341, no. 1, pp. 128-131, 2006.

[27] L. Mirabello, K. Yu, P. Kraft et al., "The association of telomere length and genetic variation in telomere biology genes," Human Mutation, vol. 31, no. 9, pp. 1050-1058, 2010.

[28] M. T. Hemann and C. W. Greider, "Wild-derived inbred mouse strains have short telomeres," Nucleic Acids Research, vol. 28, no. 22, pp. 4474-4478, 2000.
[29] R. K. Moyzis, J. M. Buckingham, L. S. Cram et al., "A highly conserved repetitive DNA sequence, (TTAGGG)(n), present at the telomeres of human chromosomes," Proceedings of the National Academy of Sciences of the United States of America, vol. 85, no. 18, pp. 6622-6626, 1988.

[30] E. H. Blackburn, "Telomeres and telomerase: their mechanisms of action and the effects of altering their functions," FEBS Letters, vol. 579, no. 4, pp. 859-862, 2005.

[31] C. B. Harley, A. B. Futcher, and C. W. Greider, "Telomeres shorten during ageing of human fibroblasts," Nature, vol. 345, no. 6274, pp. 458-460, 1990.

[32] K. Takubo, N. Izumiyama-Shimomura, N. Honma et al., "Telomere lengths are characteristic in each human individual," Experimental Gerontology, vol. 37, no. 4, pp. 523-531, 2002.

[33] C. W. Greider and E. H. Blackburn, "The telomere terminal transferase of tetrahymena is a ribonucleoprotein enzyme with two kinds of primer specificity," Cell, vol. 51, no. 6, pp. 887-898, 1987.

[34] K. Collins, R. Kobayashi, and C. W. Greider, "Purification of tetrahymena telomerase and cloning of genes encoding the two protein components of the enzyme," Cell, vol. 81, no. 5, pp. 677-686, 1995.

[35] L. S. M. Wong, H. Oeseburg, R. A. De Boer, W. H. Van Gilst, D. J. Van Veldhuisen, and P. Van Der Harst, "Telomere biology in cardiovascular disease: the TERC mouse as a model for heart failure and ageing," Cardiovascular Research, vol. 81, no. 2, pp. 244-252, 2009.

[36] M. Jaskelioff, F. L. Muller, J.-H. Paik et al., "Telomerase reactivation reverses tissuedegeneration in aged telomerasedeficient mice," Nature, vol. 469, no. 7328, pp. 102-106, 2011.

[37] E. Sahin and R. A. Depinho, "Linking functional decline of telomeres, mitochondria and stem cells during ageing," Nature, vol. 464, no. 7288, pp. 520-528, 2010.

[38] N. E. Sharpless and R. A. DePinho, "How stem cells age and why this makes us grow old," Nature Reviews Molecular Cell Biology, vol. 8, no. 9, pp. 703-713, 2007.

[39] C. M. Croce, "Oncogenes and cancer," New England Journal of Medicine, vol. 358, no. 5, pp. 502-511, 2008.

[40] J. W. Shay and W. E. Wright, "Telomeres and telomerase: implications for cancer and aging," Radiation Research, vol. 155, no. 1, pp. 188-193, 2001.

[41] W. Palm and T. De Lange, "How shelterin protects mammalian telomeres," Annual Review of Genetics, vol. 42, pp. 301-334, 2008.

[42] R. S. Vasan, S. Demissie, M. Kimura et al., "Association of leukocyte telomere length with echocardiographic left ventricular mass: the framingham heart study," Circulation, vol. 120, no. 13, pp. 1195-1202, 2009.

[43] E. Jeanclos, N. J. Schork, K. O. Kyvik, M. Kimura, J. H. Skurnick, and A. Aviv, "Telomere length inversely correlates with pulse pressure and is highly familial," Hypertension, vol. 36, no. 2, pp. 195-200, 2000.

[44] H. Aviv, M. Yusuf Khan, J. Skurnick et al., "Age dependent aneuploidy and telomere length of the human vascular endothelium," Atherosclerosis, vol. 159, no. 2, pp. 281-287, 2001.

[45] A. Benetos, J. P. Gardner, M. Zureik et al., "Short Telomeres Are Associated with Increased Carotid Atherosclerosis in Hypertensive Subjects," Hypertension, vol. 43, pp. 182-185, 2004.

[46] A. Benetos, J. P. Gardner, M. Kimura et al., "Aldosterone and telomere length in white blood cells," Journals of 
Gerontology-Series A Biological Sciences and Medical Sciences, vol. 60, no. 12, pp. 1593-1596, 2005.

[47] P. van der Harst, G. van der Steege, R. A. de Boer et al., "Telomere length of circulating leukocytes is decreased in patients with chronic heart failure," Journal of the American College of Cardiology, vol. 49, no. 13, pp. 1459-1464, 2007.

[48] S. Demissie, D. Levy, E. J. Benjamin et al., "Insulin resistance, oxidative stress, hypertension, and leukocyte telomere length in men from the Framingham Heart Study," Aging Cell, vol. 5, no. 4, pp. 325-330, 2006.

[49] A. L. Fitzpatrick, R. A. Kronmal, J. P. Gardner et al., "Leukocyte telomere length and cardiovascular disease in the cardiovascular health study," American Journal of Epidemiology, vol. 165, no. 1, pp. 14-21, 2007.

[50] C. J. O’Donnell, S. Demissie, M. Kimura et al., "Leukocyte telomere length and carotid artery intimal medial thickness: the Framingham Heart Study," Arteriosclerosis, Thrombosis, and Vascular Biology, vol. 28, no. 6, pp. 1165-1171, 2008.

[51] R. S. Vasan, S. Demissie, M. Kimura et al., "Association of leukocyte telomere length with circulating biomarkers of the renin-angiotensin-aldosterone system: the Framingham heart study," Circulation, vol. 117, no. 9, pp. 1138-1144, 2008.

[52] S. W. Brouilette, A. Whittaker, S. E. Stevens, P. Van Der Harst, A. H. Goodall, and N. J. Samani, "Telomere length is shorter in healthy offspring of subjects with coronary artery disease: support for the telomere hypothesis," Heart, vol. 94, no. 4, pp. 422-425, 2008.

[53] S. W. Brouilette, J. S. Moore, A. D. McMahon et al., "Telomere length, risk of coronary heart disease, and statin treatment in the West of Scotland Primary Prevention Study: a nested case-control study," Lancet, vol. 369, no. 9556, pp. 107-114, 2007.

[54] E. J. Kushner, B. R. Weil, O. J. Maceneaney et al., "Human aging and CD31+ T-cell number, migration, apoptotic susceptibility, and telomere le," Journal of Applied Physiology, vol. 109, pp. 1756-1761, 2010.

[55] D. Ornish, M. J. M. Magbanua, G. Weidner et al., "Changes in prostate gene expression in men undergoing an intensive nutrition and lifestyle intervention," Proceedings of the National Academy of Sciences of the United States of America, vol. 105, no. 24, pp. 8369-8374, 2008.

[56] A. Aviv, W. Chen, J. P. Gardner et al., "Leukocyte telomere dynamics: longitudinal findings among young adults in the Bogalusa Heart Study," American Journal of Epidemiology, vol. 169, no. 3, pp. 323-329, 2009.

[57] T. Kuznetsova, V. Codd, S. Brouilette et al., "Association between left ventricular mass and telomere length in a population study," American Journal of Epidemiology, vol. 172, no. 4, pp. 440-450, 2010.

[58] A. Adaikalakoteswari, M. Balasubramanyam, and V. Mohan, "Telomere shortening occurs in Asian Indian Type 2 diabetic patients," Diabetic Medicine, vol. 22, no. 9, pp. 1151-1156, 2005.

[59] A. Adaikalakoteswari, M. Balasubramanyam, R. Ravikumar, R. Deepa, and V. Mohan, "Association of telomere shortening with impaired glucose tolerance and diabetic macroangiopathy," Atherosclerosis, vol. 195, no. 1, pp. 83-89, 2007.

[60] O. S. Al-Attas, N. Al-Daghri, A. Bamakhramah, S. Shaun Sabico, P. McTernan, and T. T. K. Huang, "Telomere length in relation to insulin resistance, inflammation and obesity among Arab youth," Acta Paediatrica, International Journal of Paediatrics, vol. 99, no. 6, pp. 896-899, 2010.

[61] M. J. Sampson, M. S. Winterbone, J. C. Hughes, N. Dozio, and D. A. Hughes, "Monocyte telomere shortening and oxidative DNA damage in type 2 diabetes," Diabetes Care, vol. 29, no. 2, pp. 283-289, 2006.

[62] O. S. Al-Attas, N. M. Al-Daghri, M. S. Alokail et al., "Adiposity and insulin resistance correlate with telomere length in middle-aged Arabs: the influence of circulating adiponectin," European Journal of Endocrinology, vol. 163, no. 4, pp. 601-607, 2010.

[63] M. Satoh, Y. Ishikawa, Y. Takahashi, T. Itoh, Y. Minami, and M. Nakamura, "Association between oxidative DNA damage and telomere shortening in circulating endothelial progenitor cells obtained from metabolic syndrome patients with coronary artery disease," Atherosclerosis, vol. 198, no. 2, pp. 347-353, 2008.

[64] E. S. Epel, J. Lin, F. H. Wilhelm et al., "Cell aging in relation to stress arousal and cardiovascular disease risk factors," Psychoneuroendocrinology, vol. 31, no. 3, pp. 277-287, 2006.

[65] J. L. Tarry-Adkins, J. H. Chen, N. S. Smith, R. H. Jones, H. Cherif, and S. E. Ozanne, "Poor maternal nutrition followed by accelerated postnatal growth leads to telomere shortening and increased markers of cell senescence in rat islets," FASEB Journal, vol. 23, no. 5, pp. 1521-1528, 2009.

[66] J. L. Tarry-Adkins, M. S. Martin-Gronert, J. H. Chen, R. L. Cripps, and S. E. Ozanne, "Maternal diet influences DNA damage, aortic telomere length, oxidative stress, and antioxidant defense capacity in rats," FASEB Journal, vol. 22, no. 6, pp. 2037-2044, 2008.

[67] K. D. Salpea, P. J. Talmud, J. A. Cooper et al., "Association of telomere length with type 2 diabetes, oxidative stress and UCP2 gene variation," Atherosclerosis, vol. 209, no. 1, pp. 4250, 2010.

[68] S. Bekaert, I. Van Pottelbergh, T. De Meyer et al., “Telomere length versus hormonal and bone mineral status in healthy elderly men," Mechanisms of Ageing and Development, vol. 126, no. 10, pp. 1115-1122, 2005.

[69] A. M. Valdes, J. B. Richards, J. P. Gardner et al., "Telomere length in leukocytes correlates with bone mineral density and is shorter in women with osteoporosis," Osteoporosis International, vol. 18, no. 9, pp. 1203-1210, 2007.

[70] J. L. Sanders, J. A. Cauley, R. M. Boudreau et al., "Leukocyte telomere length is not associated with BMD, osteoporosis, or fracture in older adults: results from the health, aging and body composition study," Journal of Bone and Mineral Research, vol. 24, no. 9, pp. 1531-1536, 2009.

[71] N. L. S. Tang, J. Woo, E. W. C. Suen, C. D. Liao, J. C. S. Leung, and P. C. Leung, "The effect of telomere length, a marker of biological aging, on bone mineral density in elderly population," Osteoporosis International, vol. 21, no. 1, pp. 8997, 2010.

[72] J. S. Price, J. G. Waters, C. Darrah et al., "The role of chondrocyte senescence in osteoarthritis," Aging Cell, vol. 1, no. 1, pp. 57-65, 2002.

[73] F. Kadi and E. Ponsot, "The biology of satellite cells and telomeres in human skeletal muscle: effects of aging and physical activity," Scandinavian Journal of Medicine and Science in Sports, vol. 20, no. 1, pp. 39-48, 2010.

[74] S. Decary, C. Ben Hamida, V. Mouly, J. P. Barbet, F. Hentati, and G. S. Butler-Browne, "Shorter telomeres in dystrophic muscle consistent with extensive regeneration in young children," Neuromuscular Disorders, vol. 10, no. 2, pp. 113$120,2000$.

[75] S. Di Donna, V. Renault, C. Forestier et al., "Regenerative capacity of human satellite cells: the mitotic clock in cell transplantation," Neurological Sciences, vol. 21, no. 9, pp. S943-S951, 2000. 
[76] M. Collins, V. Renault, L. A. Grobler et al., "Athletes with exercise-associated fatigue have abnormally short muscle DNA telomeres," Medicine and Science in Sports and Exercise, vol. 35, no. 9, pp. 1524-1528, 2003.

[77] T. C. Lund, R. W. Grange, and D. A. Lowe, "Telomere shortening in diaphragm and tibialis anterior muscles of aged mdx mice," Muscle and Nerve, vol. 36, no. 3, pp. 387-390, 2007.

[78] D. Bunout, C. Backhouse, L. Leiva et al., "Relationship between protein and mitochondrial DNA oxidative injury and telomere length and muscle loss in healthy elderly subjects," Archives of Gerontology and Geriatrics, vol. 48, no. 3, pp. 335-339, 2009.

[79] A. Wernig, R. Schäfer, U. Knauf et al., "On the regenerative capacity of human skeletal muscle," Artificial Organs, vol. 29, no. 3, pp. 192-198, 2005.

[80] M. Aguennouz, G. L. Vita, S. Messina et al., "Telomere shortening is associated to TRF1 and PARP1 overexpression in Duchenne muscular dystrophy," Neurobiology of Aging. In press.

[81] L. E. Thornell, M. Lindstöm, V. Renault et al., "Satellite cell dysfunction contributes to the progressive muscle atrophy in myotonic dystrophy type 1," Neuropathology and Applied Neurobiology, vol. 35, no. 6, pp. 603-613, 2009.

[82] A. Sacco, F. Mourkioti, R. Tran et al., "Short telomeres and stem cell exhaustion model duchenne muscular dystrophy in mdx/mTR mice," Cell, vol. 143, no. 7, pp. 1059-1071, 2010.

[83] C. Werner, T. Fürster, T. Widmann et al., "Physical exercise prevents cellular senescence in circulating leukocytes and in the vessel wall," Circulation, vol. 120, no. 24, pp. 2438-2447, 2009.

[84] T. J. LaRocca, D. R. Seals, and G. L. Pierce, "Leukocyte telomere length is preserved with aging in endurance exercisetrained adults and related to maximal aerobic capacity," Mechanisms of Ageing and Development, vol. 131, no. 2, pp. 165-167, 2010.

[85] D. E. Rae, A. Vignaud, G. S. Butler-Browne et al., "Skeletal muscle telomere length in healthy, experienced, endurance runners," European Journal of Applied Physiology, vol. 109, no. 2, pp. 323-330, 2010.

[86] E. Ponsot, J. Lexell, and F. Kadi, "Skeletal muscle telomere length is not impaired in healthy physically active old women and men," Muscle and Nerve, vol. 37, no. 4, pp. 467-472, 2008.

[87] F. Kadi, E. Ponsot, K. Piehl-Aulin et al., "The effects of regular strength training on telomere length in human skeletal muscle," Medicine and Science in Sports and Exercise, vol. 40, no. 1, pp. 82-87, 2008.

[88] J. Woo, N. Tang, and J. Leung, "No association between physical activity and telomere length in an elderly Chinese population 65 years and older," Archives of Internal Medicine, vol. 168, no. 19, pp. 2163-2164, 2008.

[89] Y. A. Shin, J. H. Lee, W. Song, and T. W. Jun, "Exercise training improves the antioxidant enzyme activity with no changes of telomere length," Mechanisms of Ageing and Development, vol. 129, no. 5, pp. 254-260, 2008.

[90] E. Puterman, J. Lin, E. Blackburn, A. O’Donovan, N. Adler, and E. Epel, "The power of exercise: buffering the effect of chronic stress on telomere length," PLOS ONE, vol. 5, no. 5, Article ID e10837, 2010.

[91] H. Zhu, X. Wang, B. Gutin et al., "Leukocyte telomere length in healthy caucasian and african-american adolescents: relationships with race, sex, adiposity, adipokines, and physical activity," Journal of Pediatrics, vol. 158, no. 2, pp. 215-220, 2011.

[92] Z. Song, G. von Figura, Y. Liu et al., "Lifestyle impacts on the aging-associated expression of biomarkers of DNA damage and telomere dysfunction in human blood," Aging cell, vol. 9, no. 4, pp. 607-615, 2010.

[93] Z. Radak, A. W. Taylor, M. Sasvari et al., "Telomerase activity is not altered by regular strenuous exercise in skeletal muscle or by sarcoma in liver of rats," Redox Report, vol. 6, no. 2, pp. 99-103, 2001.

[94] E. S. Epel, E. H. Blackburn, J. Lin et al., "Accelerated telomere shortening in response to life stress," Proceedings of the National Academy of Sciences of the United States of America, vol. 101, no. 49, pp. 17312-17315, 2004.

[95] H. Jiang, E. Schiffer, Z. Song et al., "Proteins induced by telomere dysfunction and DNA damage represent biomarkers of human aging and disease," Proceedings of the National Academy of Sciences of the United States of America, vol. 105, no. 32, pp. 11299-11304, 2008.

[96] K. Nosaka and P. M. Clarkson, "Muscle damage following repeated bouts of high force eccentric exercise," Medicine and Science in Sports and Exercise, vol. 27, no. 9, pp. 1263-1269, 1995.

[97] F. Ambrosio, F. Kadi, J. Lexell, G. Kelley Fitzgerald, M. L. Boninger, and J. Huard, "The effect of muscle loading on skeletal muscle regenerative potential: an update of current research findings relating to aging and neuromuscular pathology," American Journal of Physical Medicine and Rehabilitation, vol. 88, no. 2, pp. 145-155, 2009.

[98] S. M. Roth, G. F. Martel, F. M. Ivey et al., "Skeletal muscle satellite cell characteristics in young and older men and women after heavy resistance strength training," Journals of Gerontology-Series A Biological Sciences and Medical Sciences, vol. 56, no. 6, pp. B240-B247, 2001.

[99] H. Y. Chung, M. Cesari, S. Anton et al., "Molecular inflammation: underpinnings of aging and age-related diseases," Ageing Research Reviews, vol. 8, no. 1, pp. 18-30, 2009.

[100] M. M. Kanter, R. L. Hamlin, and D. V. Unverferth, "Effect of exercise training on antioxidant enzymes and cardiotoxicity of doxorubicin," Journal of Applied Physiology, vol. 59, no. 4, pp. 1298-1303, 1985.

[101] LI. L. Ji, "Modulation of skeletal muscle antioxidant defense by exercise: role of redox signaling," Free Radical Biology and Medicine, vol. 44, no. 2, pp. 142-152, 2008.

[102] L. I. L. Ji, M. C. Gomez-Cabrera, and J. Vina, "Exercise and hormesis: activation of cellular antioxidant signaling pathway," Annals of the New York Academy of Sciences, vol. 1067, no. 1, pp. 425-435, 2006.

[103] M. Pollicita, C. Muscoli, A. Sgura et al., "Apoptosis and telomeres shortening related to HIV-1 induced oxidative stress in an astrocytoma cell line," BMC Neuroscience, vol. 10, article 51, 2009.

[104] V. Serra, T. Grune, N. Sitte, G. Saretzki, and T. Von Zglinicki, "Telomere length as a marker of oxidative stress in primary human fibroblast cultures," Annals of the New York Academy of Sciences, vol. 908, pp. 327-330, 2000.

[105] V. Serra, T. Von Zglinicki, M. Lorenz, and G. Saretzki, "Extracellular superoxide dismutase is a major antioxidant in human fibroblasts and slows telomere shortening," Journal of Biological Chemistry, vol. 278, no. 9, pp. 6824-6830, 2003.

[106] T. Von Zglinicki, V. Serra, M. Lorenz et al., "Short telomeres in patients with vascular dementia: an indicator of low antioxidative capacity and a possible risk factor?" Laboratory Investigation, vol. 80, no. 11, pp. 1739-1747, 2000. 
[107] S. Kawanishi and S. Oikawa, "Mechanism of telomere shortening by oxidative stress," Annals of the New York Academy of Sciences, vol. 1019, pp. 278-284, 2004.

[108] P. J. Rochette and D. E. Brash, "Human telomeres are hypersensitive to UV-induced DNA damage and refractory to repair," PLoS Genetics, vol. 6, no. 4, Article ID e1000926, 2010.

[109] N. Büchner, T. C. Zschauer, M. Lukosz, J. Altschmied, and J. Haendeler, "Downregulation of mitochondrial telomerase reverse transcriptase induced by $\mathrm{HO}$ is Src kinase dependent," Experimental Gerontology, vol. 45, no. 7-8, pp. 558$562,2010$.

[110] J. Haendeler, S. Dröse, N. Büchner et al., "Mitochondrial telomerase reverse transcriptase binds to and protects mitochondrial DNA and function from damage," Arteriosclerosis, Thrombosis, and Vascular Biology, vol. 29, no. 6, pp. 929-935, 2009.

[111] M. J. Chen and A. A. Russo-Neustadt, "Nitric oxide signaling participates in norepinephrine-induced activity of neuronal intracellular survival pathways," Life Sciences, vol. 81, no. 16, pp. 1280-1290, 2007.

[112] M. Barbieri, G. Paolisso, M. Kimura et al., "Higher circulating levels of IGF-1 are associated with longer leukocyte telomere length in healthy subjects," Mechanisms of Ageing and Development, vol. 130, no. 11-12, pp. 771-776, 2009.

[113] U. Berg and P. Bang, "Exercise and circulating insulin-like growth factor I," Hormone Research, vol. 62, supplement 1, pp. 50-58, 2004.

[114] D. G. Hardie, "Energy sensing by the AMP-activated protein kinase and its effects on muscle metabolism," Proceedings of the Nutrition Society, vol. 70, no. 1, pp. 92-99, 2011.

[115] C. A. Witczak, C. G. Sharoff, and L. J. Goodyear, "AMPactivated protein kinase in skeletal muscle: from structure and localization to its role as a master regulator of cellular metabolism," Cellular and Molecular Life Sciences, vol. 65, no. 23, pp. 3737-3755, 2008.

[116] H. Mascher, H. Andersson, P.-A. Nilsson, B. Ekblom, and E. Blomstrand, "Changes in signalling pathways regulating protein synthesis in human muscle in the recovery period after endurance exercise," Acta Physiologica, vol. 191, no. 1, pp. 67-75, 2007.

[117] G. Terzis, G. Georgiadis, G. Stratakos et al., "Resistance exercise-induced increase in muscle mass correlates with p70S6 kinase phosphorylation in human subjects," European Journal of Applied Physiology, vol. 102, no. 2, pp. 145-152, 2008.

[118] J. Apfeld, G. O'Connor, T. McDonagh, P. S. DiStefano, and R. Curtis, "The AMP-activated protein kinase AAK-2 links energy levels and insulin-like signals to lifespan in C. elegans," Genes and Development, vol. 18, no. 24, pp. 3004 3009, 2004.

[119] M. V. Blagosklonny, "TOR-driven aging: speeding car without brakes," Cell Cycle, vol. 8, no. 24, pp. 4055-4059, 2009.

[120] S. R. Narala, R. C. Allsopp, T. B. Wells et al., "SIRT1 acts as a nutrient-sensitive growth suppressor and its loss is associated with increased AMPK and telomerase activity," Molecular Biology of the Cell, vol. 19, no. 3, pp. 1210-1219, 2008.

[121] J. Choi, S. R. Fauce, and R. B. Effros, "Reduced telomerase activity in human T lymphocytes exposed to cortisol," Brain, Behavior, and Immunity, vol. 22, no. 4, pp. 600-605, 2008.

[122] P. Spallarossa, P. Altieri, C. Aloi et al., "Doxorubicin induces senescence or apoptosis in rat neonatal cardiomyocytes by regulating the expression levels of the telomere binding factors 1 and 2," American Journal of Physiology, vol. 297, no. 6, pp. H2169-H2181, 2009.

[123] K. S. C. Röckl, C. A. Witczak, and L. J. Goodyear, "Signaling mechanisms in skeletal muscle: acute responses and chronic adaptations to exercise," IUBMB Life, vol. 60, no. 3, pp. 145153, 2008.

[124] P. Muñoz, R. Blanco, G. De Carcer et al., “TRF1 controls telomere length and mitotic fidelity in epithelial homeostasis," Molecular and Cellular Biology, vol. 29, no. 6, pp. 1608$1625,2009$.

[125] Z. Lou, J. Wei, H. Riethman et al., “Telomere length regulates ISG15 expression in human cells," Aging, vol. 1, no. 7, pp. 608-621, 2009.

[126] M. Recht, E. C. Borden, and E. Knight, "A human 15-kDa IFN-induced protein induces the secretion of IFN- $\gamma$," Journal of Immunology, vol. 147, no. 8, pp. 2617-2623, 1991.

[127] J. D'Cunha, E. Knight, A. L. Haas, R. L. Truitt, and E. C. Borden, "Immunoregulatory properties of ISG15, an interferon-induced cytokine," Proceedings of the National Academy of Sciences of the United States of America, vol. 93, no. 1, pp. 211-215, 1996.

[128] R. N. Bhattacharjee, B. Banerjee, S. Akira, and M. P. Hande, "Telomere-mediated chromosomal instability triggers TLR4 induced inflammation and death in mice," PLoS ONE, vol. 5, no. 7, Article ID e11873, 2010.

[129] M. C. Calle and M. L. Fernandez, "Effects of resistance training on the inflammatory response," Nutrition Research and Practice, vol. 4, pp. 259-269, 2010.

[130] H. E. Ploeger, T. Takken, M. H. de Greef, and B. W. Timmons, "The effects of acute and chronic exercise on inflammatory markers in children and adults with a chronic inflammatory disease: a systematic review," Exercise Immunology Review, vol. 15, pp. 6-41, 2009.

[131] B. K. Pedersen and C. Brandt, "The role of exercise-induced myokines in muscle homeostasis and the defense against chronic diseases," Journal of Biomedicine and Biotechnology, vol. 2010, Article ID 520258, 2010.

[132] M. A. Blasco, "Mice with bad ends: mouse models for the study of telomeres and telomerase in cancer and aging," EMBO Journal, vol. 24, no. 6, pp. 1095-1103, 2005.

[133] M. A. Blasco, "Telomeres and human disease: ageing, cancer and beyond," Nature Reviews Genetics, vol. 6, no. 8, pp. 611622, 2005.

[134] J. Karlseder, L. Kachatrian, H. Takai et al., "Targeted deletion reveals an essential function for the telomere length regulator Trf1," Molecular and Cellular Biology, vol. 23, no. 18, pp. 6533-6541, 2003.

[135] H. Takai, A. Smogorzewska, and T. De Lange, "DNA damage foci at dysfunctional telomeres," Current Biology, vol. 13, no. 17, pp. 1549-1556, 2003.

[136] P. Martínez, M. Thanasoula, P. Muñoz et al., "Increased telomere fragility and fusions resulting from TRF1 deficiency lead to degenerative pathologies and increased cancer in mice," Genes and Development, vol. 23, no. 17, pp. 20602075, 2009.

[137] H. Oeseburg, R. A. De Boer, W. H. Van Gilst, and P. Van Der Harst, "Telomere biology in healthy aging and disease," Pflugers Archiv, vol. 459, no. 2, pp. 259-268, 2010. 


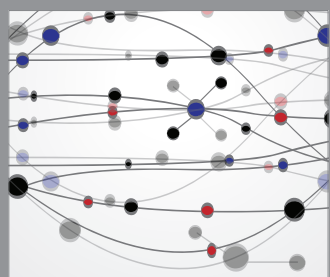

The Scientific World Journal
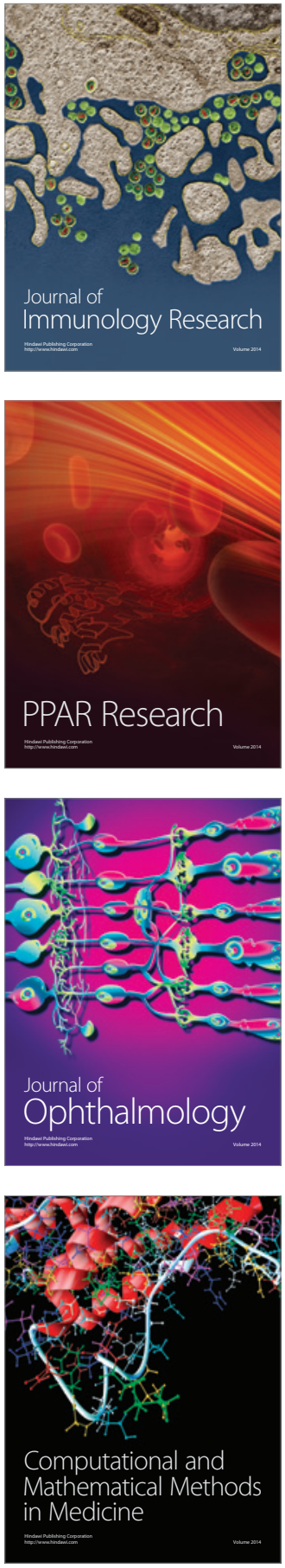

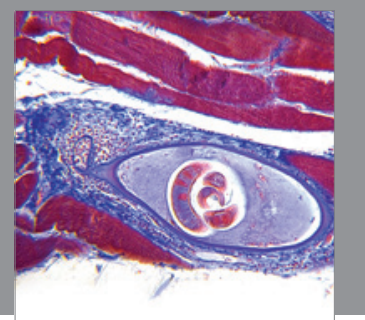

Gastroenterology

Research and Practice
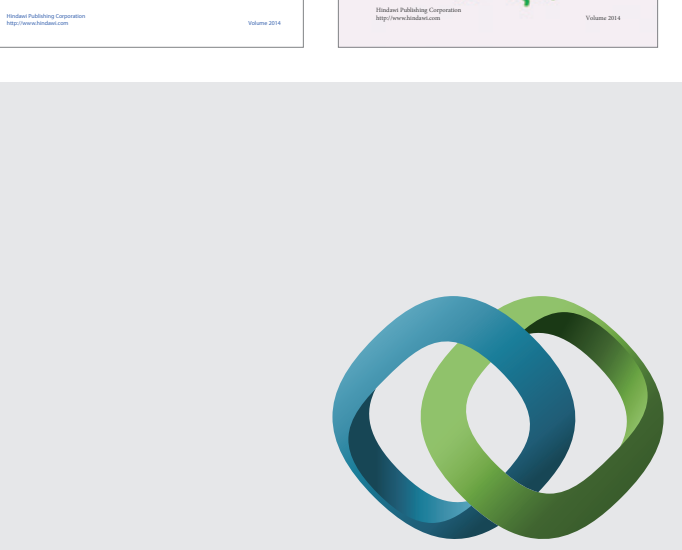

\section{Hindawi}

Submit your manuscripts at

http://www.hindawi.com
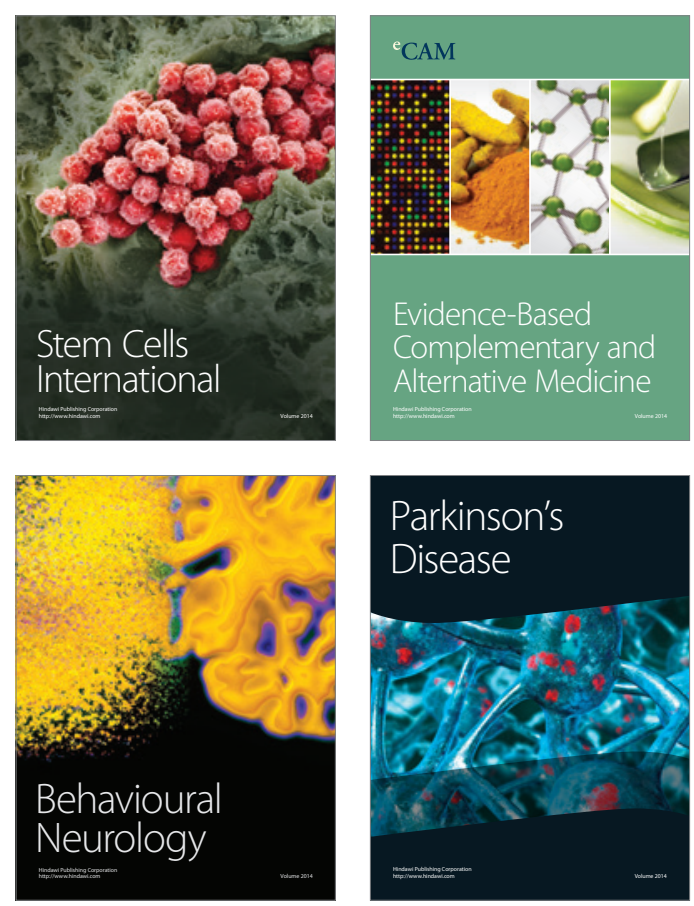

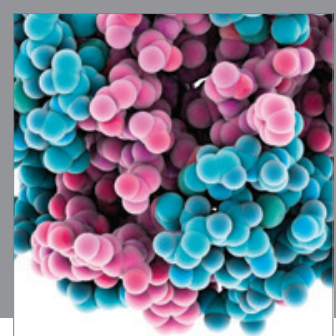

Journal of
Diabetes Research

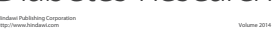

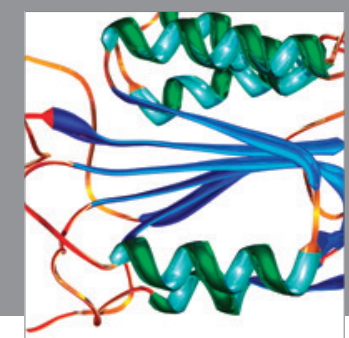

Disease Markers
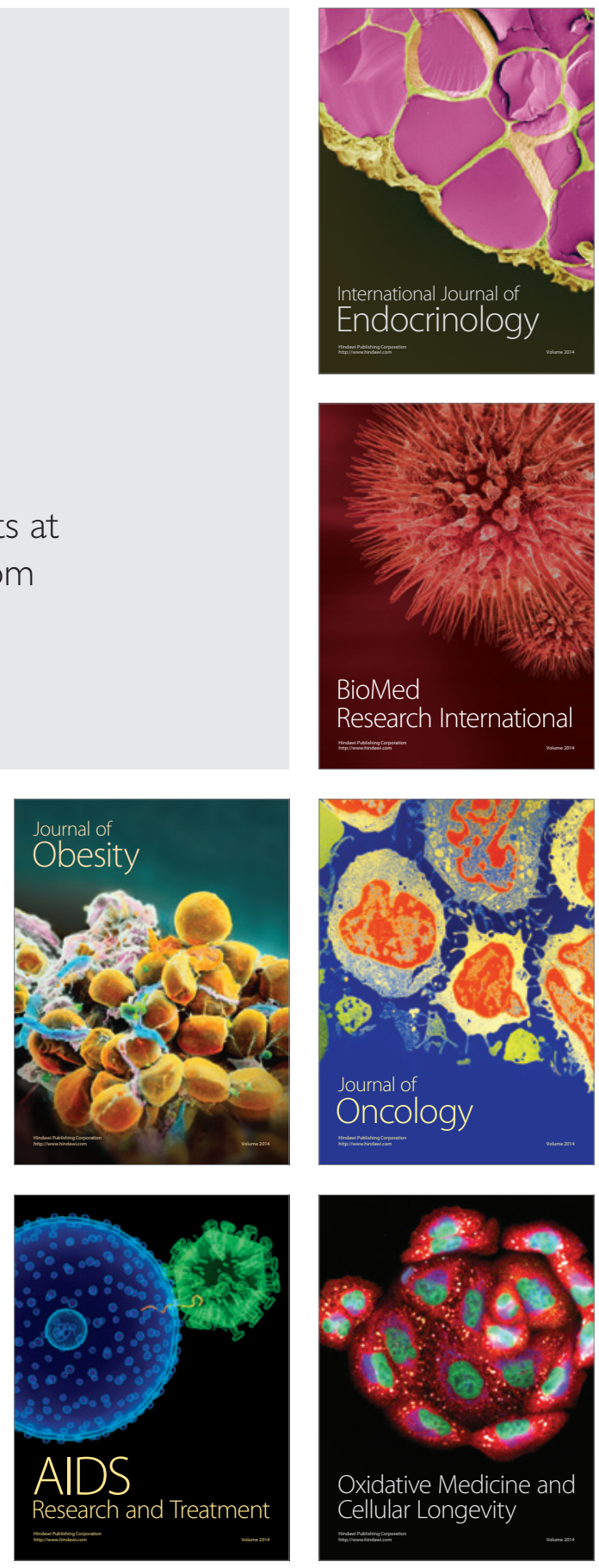